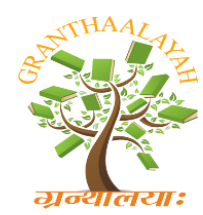

INTERNATIONAL JOURNAL OF RESEARCH GRANTHAALAYAH

A knowledge Repository

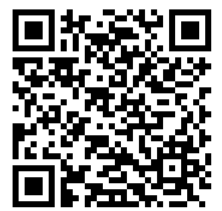

Science

\title{
PERFORMANCE OF UPLAND NERICA AND NON -NERICA RICE ENOTYPES IN MULTI-ENVIRONMENT YIELD TRIALS AS ANALYSED USING GGEBIPLOT MODEL
}

\author{
Sewagegne Tariku ${ }^{* 1}$, Tadesse Lakew ${ }^{2}$ \\ ${ }^{*} 1,2$ Adet Agricultural Research Center, P.O.Box=8, Bahir Dar, ETHIOPIA
}

\begin{abstract}
Ten upland New Rice for Africa (NERICA) and three upland non-NERICA rice genotypes were evaluated at three locations of six environments in north western Ethiopia from 2009 to 2011 to identify stable and high yielding genotypes and mega environments. Randomized complete block design with three replications was used. GGE biplot methodology was used for graphically display of yield data. The combined analysis of variance revealed that environment (E) accounted for $32.2 \%$ of the total variation while $G$ and GEI captured $20.3 \%$ and $21.1 \%$, respectively. The first 2 principal components (PC1 and PC2) were used to create a 2dimensional GGE biplot and explained $56.9 \%$ and $20.6 \%$ of GGE sum of squares (SS), respectively. Genotypic PCI scores >0 detected the adaptable and/or higher-yielding genotypes, while PC1 scores <0 discriminated the non-adaptable and/or lower-yielding ones. Unlike genotypic PC1 scores, near-zero PC2 scores identified stable genotypes, whereas absolute larger PC2 scores detected the unstable ones. On the other hand, environmental PC1 scores were related to non-crossover type GEIs and the PC2 scores to the crossover type. Among the tested genotypes 3,2,11, 13, 8 were found to be desirable in terms of higher yielding ability and stability in descending order. Based on GGEbiplot analysis, the test environments were classified in to three mega-environments. Mega -1 included environment WO-1 (Woreta) with genotype 9 as a winner; Mega-2 constituted environments such as WO3 and WO-5 (Woreta) with genotype 2 as a winner and Mega-3 contained environments including PA-2,PA-6(Pawe) and ME-7(Metema) with genotype 8 as winner. However, it is not justifiable to consider two mega-environments within one specified area. So that mega environments 1 and 2 should be treated as one. The result of this study can be used as a driving force for the national rice breeding program to design breeding strategy that can address the request of different stakeholders for improved varieties. Among the tested genotypes in this study, three candidate genotypes (2, 3 and 8$)$ were selected and verified considering their better performance. Of which, genotype 2 has been officially released for large scale production with the common name 'NERICA-12',
\end{abstract}

Keywords:

Multi-environment trials, GGE biplot analysis, $G \times E$ interaction, upland NERICA rice. 
Cite This Article: Sewagegne Tariku, and Tadesse Lakew, "PERFORMANCE OF UPLAND NERICA AND NON -NERICA RICE ENOTYPES IN MULTI-ENVIRONMENT YIELD TRIALS AS ANALYSED USING GGEBIPLOT MODEL" International Journal of Research Granthaalayah, Vol. 4, No. 3 (2016): 146-158.

\section{INTRODUCTION}

Among the target commodities that have received due attention in promotion of agricultural production, rice is considered as the "millennium crop" expected to contribute in ensuring food security in Ethiopia (MoARD, 2010). Though introduced recently, the importance of rice is being well recognized both by the Government and different stakeholders as the crop is treated as one of the major national research projects, the trend of area coverage and total production is on the increase, the number of small scale farmers and private investors involving in production and processing and the request for improved rice varieties is increasing.

Variety development is one of the major research focuses of the national rice research project to address the increasing demand for improved varieties and to keep sustainable rice production in the country. The general rice breeding scheme includes evaluating a number of genotypes at various stages and testing selected ones at several environments. The multienvironment testing usually results in genotype-by-environment interactions that often complicate the interpretation of results obtained and reduces efficiency in selecting the best genotypes. This interaction is the result of changes in cultivar's relative performance across environments, due to differential responses of the genotypes to various edaphic, climatic and biotic factors. Gauch and Zobel (1996) explained the importance of GEI as: "Were there no interaction, a single variety any other crop would yield the most the world over, and furthermore the variety trial need be conducted at only one location to provide universal results" Information on genotype $\times$ environment interaction leads to successful evaluation of genotypes and test environments. Thus, analysis of genotype -by- environment data from multienvironment trials has been an important component of plant breeding and cultivar recommendation (Yan, 2011).

Different statistical models are used to describe GE interaction and facilitate genotype recommendations in MET. These models have been classified as univariate versus multivariate approaches (Flores et al., 1998). Multivariate statistical approaches explore multi-directional aspects of GE interaction and attempt to extract more information from GE interaction components (Gauch and Zobel, 1996; Gauch et al., 2008). Several multivariate procedures have been proposed to explore GE interaction including principal component analysis (PCA), additive main effects and multiplicative interactions (AMMI) and genotype plus GE interaction biplot (GGE biplot) analysis (Yan et al., 2000; Zoble et al., 1988). Of which GGEbiplot analysis is a new technique for graphical display of GE interaction pattern of MET data with many advantages (Yan et al., 2000).

GGE biplot analysis considers both genotype (G) and GE interaction effects and graphically displays GE interaction in a two way table (Yan et al., 2000). GGE biplot is an effective method based on principal component analysis (PCA) to fully explore MET data. It allows visual examination of the relationships among the test environments, genotypes and the GE 
interactions. It is an effective tool for: (i) mega-environment analysis (e.g. "which-won-where" pattern), where by specific genotypes can be recommended to specific mega-environments (Yan and Kang, 2003; Yan and Tinker, 2006), (ii) genotype evaluation (the mean performance and stability), and (iii) environmental evaluation (the power to discriminate among genotypes in target environments) (Ding et al., 2007). It has been proposed that GGE biplot analysis was a useful method for the analysis of GE interactions and had been exploited in the variety evaluation of wheat (Yan et al., 2000), Maize (Fan et al., 2007) and rice (Balestre et al.,2010). Therefore, the objectives of this research activity were:

- To interpret the magnitude and causes of genotype $(\mathrm{G})$, environment(E) and GE interaction on yield performances of 20 rice genotypes tested across 10 environments,

- To evaluate rice genotypes for their yield performance and stability and select and release genotypes with high grain yield, stability and other desirable traits.

- To examine the possible existence of different mega environments and the wining genotype for each mega environment.

\section{MATERIALS AND METHODS}

\section{PLANTING MATERIALS AND TRIAL MANAGEMENT}

Ten upland NERICA and three upland non-NERICA rice genotypes obtained from Africa Rice Center and Madagascar, respectively (Table 1) were evaluated from 2009 to 2011 at three locations of six environments including, Woreta (WO-1,WO-3 and WO-5), Pawe (PA-2 and PA-6) and Metema (NE-7). The locations where the experiment was conducted differ in soil type, altitude, temperature, rainfall received per annum (Table 2). Randomized complete block design (RCBD) with three replications was used. Each plot had six rows of $5 \mathrm{~m}$ length and spaced $0.2 \mathrm{~m}$ apart. Fertilizer (UREA and DAP) was applied as per the recommendation of each respective location.Total DAP was applied at planting while urea was applied one third at planting, one third at tillering and the remaining one third at panicle initiation. A dry seed rate of $60 \mathrm{~kg} \mathrm{ha}^{-1}$ was used and seeds were drilled in a row. Plantings were done in the main cropping season (rainy season) following the optimal dates in each respective location. All relevant agronomic practices were applied whenever necessary. Data on grain yield and some other yield components were collected (Table 1). However, this paper is reporting mainly on grain yield data ( $\mathrm{t} \mathrm{ha}{ }^{-1}$ at $14 \%$ moisture level and estimated on the basis of four central harvestable rows).

\section{STATISTICAL ANALYSIS}

Analysis of variance was done using system analysis software (SAS, 2004). Before grain yield data analysis, homogeneity of variance was determined by Bartlet's test (Gomez and Gomez, 1984). The data were found to be homogenous and subjected to combined analysis of variance (ANOVA) to determine the effects of environment (E), genotype $(\mathrm{G})$, and their interactions. The data were graphically analyzed for interpreting GE interaction using the GGEbiplot software (GGEbiplot, 2009). GGE biplot methodology, which is composed of two concepts, the biplot concept (Gabriel, 1971) and the GGE concept (Yan et al., 2000), was used to visually analyze the MET data. This methodology uses a biplot to show the factors ( $G$ and GE) that are important in genotype evaluation and that are also the sources of variation in GE interaction analysis of MET 
data (Yan,2001). The graphs were generated based on (i) "which-won-where" pattern, (ii) ranking of genotypes on the basis of yield and stability, (iii) comparison of genotypes to an ideal genotype,(iv) genotype-environment relationships (v) relationships between testing environments and (vi) discriminating ability and representativeness of the test environments

Table 1: List of testing upland NERICA and unland non-NERICA rice genotypes with their mean performance for grain yield and some other agronomic traits across six environments

\begin{tabular}{|c|c|c|c|c|c|c|c|c|c|c|c|}
\hline \multicolumn{2}{|l|}{$\begin{array}{l}\text { Genotype } \\
\text { Name }\end{array}$} & \multirow{2}{*}{\multicolumn{2}{|c|}{ Source }} & \multirow{2}{*}{$\begin{array}{l}\text { Days to } \\
\text { maturity }\end{array}$} & \multirow{2}{*}{$\begin{array}{l}\text { Panicle } \\
\text { length } \\
\text { (cm) }\end{array}$} & \multirow{2}{*}{$\begin{array}{l}\text { Plant } \\
\text { height } \\
\text { (cm) }\end{array}$} & \multirow[b]{2}{*}{$\begin{array}{l}\% \\
\text { effec } \\
\text { tiveti } \\
\text { Ilers/ } \\
\text { plant }\end{array}$} & \multirow{2}{*}{$\begin{array}{l}\text { No. of } \\
\text { grain } \\
\text { s/pani } \\
\text { cle }\end{array}$} & \multirow{3}{*}{$\begin{array}{l}\% \\
\text { filled } \\
\text { grain } \\
\text { s/pani } \\
\text { cle } \\
93.4^{\text {abc }}\end{array}$} & \multirow{3}{*}{$\begin{array}{l}\text { Thous } \\
\text { and } \\
\text { grain } \\
\text { wt } \\
\text { (gm) } \\
26.4^{\text {cde }}\end{array}$} & \multirow{2}{*}{$\begin{array}{l}\text { Grain } \\
\text { yield } \\
\text { (t/ha" } \\
\text { i) }\end{array}$} \\
\hline Name & $\begin{array}{l}\text { cod } \\
e^{-}\end{array}$ & & & & & & & & & & \\
\hline $\begin{array}{l}\text { UPLAND } \\
\text { NERICA-11 }\end{array}$ & 1 & $\begin{array}{l}\text { Africa } \\
\text { Center }\end{array}$ & Rice & $130.4^{\mathrm{abc}}$ & $27.6^{\mathrm{f}}$ & $68.0^{\mathrm{ef}}$ & 94.9 & 128.5 & & & $2.4^{\mathrm{efg}}$ \\
\hline $\begin{array}{l}\text { UPLAND } \\
\text { NERICA-12 }\end{array}$ & 2 & $\begin{array}{l}\text { Africa } \\
\text { Center }\end{array}$ & Rice & $134.6^{\mathrm{a}}$ & $32.8^{\mathrm{ab}}$ & $83.5^{\mathrm{ab}}$ & 94.8 & 132.0 & $94.0^{\mathrm{ab}}$ & 29.2 & $3.6^{\mathrm{ab}}$ \\
\hline $\begin{array}{l}\text { UPLAND } \\
\text { NERICA-13 }\end{array}$ & 3 & $\begin{array}{l}\text { Africa } \\
\text { Center }\end{array}$ & Rice & $131.3^{\mathrm{ab}}$ & $32.8^{\mathrm{ab}}$ & $81.2^{\mathrm{bc}}$ & 94.5 & 118.1 & $94.0^{\mathrm{ab}}$ & $29.0^{\mathrm{ab}}$ & $3.7^{\mathrm{a}}$ \\
\hline $\begin{array}{l}\text { UPLAND } \\
\text { NERICA-14 }\end{array}$ & 4 & $\begin{array}{l}\text { Africa } \\
\text { Center }\end{array}$ & Rice & $126.3^{\text {cd }}$ & $31.8^{\mathrm{abc}}$ & $73.0^{\mathrm{d}}$ & 94.1 & 126.1 & $95.0^{\mathrm{a}}$ & $26.1^{\text {cdef }}$ & $2.8^{\mathrm{de}}$ \\
\hline $\begin{array}{l}\text { UPLAND } \\
\text { NERICA-15 }\end{array}$ & 5 & $\begin{array}{l}\text { Africa } \\
\text { Center }\end{array}$ & Rice & $125.5^{\mathrm{d}}$ & $32.1^{\mathrm{abc}}$ & $73.6^{\mathrm{d}}$ & 96.1 & 123.8 & $94.1^{\mathrm{ab}}$ & $26.9^{\mathrm{cd}}$ & $3.0^{\mathrm{cd}}$ \\
\hline $\begin{array}{l}\text { UPLAND } \\
\text { NERICA-16 }\end{array}$ & 6 & $\begin{array}{l}\text { Africa } \\
\text { Center }\end{array}$ & Rice & $125.6^{\mathrm{cd}}$ & $28.0^{\mathrm{f}}$ & 65.1f & 94.7 & 119.7 & $91.6^{\mathrm{c}}$ & $24.7^{\mathrm{ef}}$ & $2.3^{\mathrm{fg}}$ \\
\hline $\begin{array}{l}\text { UPLAND } \\
\text { NERICA-17 }\end{array}$ & 7 & $\begin{array}{l}\text { Africa } \\
\text { Center }\end{array}$ & Rice & $126.3^{\text {cd }}$ & $27.4^{\mathrm{f}}$ & $65.6 \mathrm{f}$ & 98.0 & 127.9 & $92.3^{b c}$ & $25.3^{\mathrm{def}}$ & $2.5^{\mathrm{ef}}$ \\
\hline $\begin{array}{l}\text { UPLAND } \\
\text { NERICA-18 }\end{array}$ & 8 & $\begin{array}{l}\text { Africa } \\
\text { Center }\end{array}$ & Rice & $128.6^{\mathrm{bcd}}$ & $23.8^{\mathrm{a}}$ & $86.9^{\mathrm{a}}$ & 92.1 & 134.7 & $94.8^{\mathrm{a}}$ & $27.8^{\mathrm{dc}}$ & $3.6^{\mathrm{ab}}$ \\
\hline FOFIFA-4129 & 9 & Madagas & & $126.8^{\mathrm{bcd}}$ & $31.2^{\mathrm{bcd}}$ & $80.9^{\mathrm{bc}}$ & 96.5 & 125.8 & $94.0^{\mathrm{ab}}$ & $30.0^{\mathrm{a}}$ & $3.2^{\mathrm{abcd}}$ \\
\hline FOFIFA-3737 & 10 & Madagas & & $127.6^{\mathrm{bcd}}$ & $30.0^{\text {cde }}$ & $78.4^{\mathrm{c}}$ & 94.6 & 132.7 & $94.2^{\mathrm{ab}}$ & $30.0^{\mathrm{a}}$ & $3.1^{\mathrm{bcd}}$ \\
\hline FOFIFA-3730 & 11 & Madagas & & 130.3abcd & $31.3^{\mathrm{bcd}}$ & $81.2^{\mathrm{bc}}$ & 94.3 & 122.7 & $94.7^{\mathrm{a}}$ & $29.7^{\mathrm{ab}}$ & $3.4^{\mathrm{abc}}$ \\
\hline NERICA-10 & 12 & $\begin{array}{l}\text { Africa } \\
\text { Center }\end{array}$ & Rice & $128.2^{\text {bcd }}$ & $27.6^{\mathrm{f}}$ & $67.0^{\mathrm{f}}$ & 93.4 & 121.1 & $89.2^{\mathrm{d}}$ & $24.17^{\mathrm{f}}$ & $2.0^{\mathrm{g}}$ \\
\hline NERICA-4(check) & 13 & $\begin{array}{l}\text { Africa } \\
\text { Center }\end{array}$ & Rice & $127.0^{\mathrm{bcd}}$ & $29.2^{\mathrm{def}}$ & $71.4^{\mathrm{de}}$ & 95.5 & 134.8 & $94.4^{\mathrm{a}}$ & $25.5^{\mathrm{def}}$ & $3.4^{\mathrm{abc}}$ \\
\hline Mean & & & & 128.3 & 30.4 & 75.1 & 94.9 & 126.8 & 93.5 & 27.3 & 3.0 \\
\hline CV $(\%)$ & & & & 5.7 & 11.2 & 7.9 & 5.9 & 26.6 & 3.4 & 11.6 & 24 \\
\hline Genotype (GEN) & & & & ** & $* *$ & $* *$ & NS & NS & ** & $* *$ & ** \\
\hline Environment (ENV) & & & & NS & ** & ** & ** & ** & ** & NS & ** \\
\hline GEN*ENV & & & & NS & $* *$ & $* *$ & NS & NS & $* *$ & NS & ** \\
\hline
\end{tabular}

Table 2: Description of experimental locations

\begin{tabular}{llll}
\hline $\begin{array}{l}\text { Agro ecological } \\
\text { character }\end{array}$ & \multicolumn{2}{c}{ Locations } \\
\cline { 2 - 4 } & Woreta & Pawe & Metema \\
Latitude & $11^{0} 58^{\prime} \mathrm{N}$ & $11^{0} 9^{\prime} \mathrm{N}$ & $12^{0} 58^{\prime} \mathrm{N}$ \\
\hline $\begin{array}{l}\text { Longitude } \\
\text { Altitude (masl) }\end{array}$ & $37^{0} 41^{\prime} \mathrm{E}$ & $36^{0} 3^{\prime} \mathrm{E}$ & $36^{0} 12^{\prime} \mathrm{E}$ \\
$\begin{array}{l}\text { Annual } \\
\text { rainfall(mm) }\end{array}$ & 1300 & 1050 & 685 \\
\hline
\end{tabular}




\begin{tabular}{|c|c|c|c|}
\hline $\begin{array}{l}\text { Mean maximum } \\
\text { temp. }\left({ }^{0} \mathrm{C}\right)\end{array}$ & 27.9 & 32.75 & 37 \\
\hline $\begin{array}{l}\text { Mean minimum } \\
\text { temp }\left({ }^{0} \mathrm{C}\right)\end{array}$ & 11.5 & 17.17 & 25 \\
\hline Soil type & Vertisol & Nitosol & Luvisol \\
\hline
\end{tabular}

Source: Agricultural development office of each respective location

\section{RESULTS and DISCUSSION}

\section{ANALYSIS OF VARIANCE}

The combined analysis of variance showed significant difference among the tested genotypes in days to maturity, panicle length, plant height, $\%$ fertile grains/panicle and thousand grain weight except \% effective tillers/plant and no. of grains /panicle (Table 1). Upland non-NERICA rice genotypes showed better performance than some of upland NERICA rice genotypes in terms of number of grains/panicle, thousand grain weight and grain yield (Table 1). The combined analysis of variance for grain yield is presented in Table 3. Genotype (G), environment (E) and genotype $\times$ environment interaction (GEI) were significant $(\mathrm{P} \leq 0.01)$. Such statistical interaction resulted from the changes in the relative ranking of the genotypes from one environment to another. The significant genotype $\times$ environment interaction effects demonstrated that genotypes responded differently to the variation in environmental conditions of location indicating the necessity of testing rice varieties at multiple locations. This also shows the difficulties encountered by breeders in selecting new varieties for release. The factors explained (\%) show that rice grain yield was affected by environment (32.2\%), genotype (20.3\%) and their interaction (21.1\%). Gauch and Zobel (1997) reported that, in normal MEYTs, E accounts for about $80 \%$ of the total variation, while $\mathrm{G}$ and GE each account for about $10 \%$. However, it is $\mathrm{G}$ and GE that are relevant to cultivar evaluation (Yan et al. 2002). The significant GE interaction in this study suggests the possible existence of different mega-environments (Yan and Kang, 2003).

It is commonly reported that MET data may constitute a mixture of cross over and non-cross over types of GE interaction. The former indicates the change in yield ranking of genotypes across environments and the later shows constant yield rankings of genotypes across environment (Yan and Hunt, 2001; Matus-Cadiz et al., 2003). In this study inconsistency in grain yield ranking from environment to environment was observed (Table 4) indicating the presence of possible cross over GEI as described by Yan and hunt (2001) and Kaya et al (2006). However, crossover GEI is not always the case. Genotype 2 was the highest yielding in environments WO3 (Woreta) and PA-6 (Pawe). Moreover, genotype 8 exhibited the highest yield potential in environments PA-2 (Pawe) and ME-7 (Metema). These results in differential change of yield mean but not of ranking of genotypes showed that GEI may also have a non-crossover nature. The mean grain yield of the 13 genotypes ranged from 2.00 to $3.7 \mathrm{t} \mathrm{ha}^{-1}$ and the highest grain yield was obtained from genotype 3 and the lowest from genotype 12 (Table 1). 
Table 3: Combined analysis of variance of grain yield data ( $\mathrm{t} / \mathrm{ha}-1)$ of 13 rice genotypes tested across 6 environments

\begin{tabular}{|c|c|c|c|c|}
\hline $\begin{array}{l}\text { Source } \\
\text { variation }\end{array}$ & $\begin{array}{l}\text { Degree of } \\
\text { freedom }\end{array}$ & $\begin{array}{l}\text { Sum of } \\
\text { squares }\end{array}$ & $\begin{array}{l}\text { Mean } \\
\text { squares }\end{array}$ & $\begin{array}{l}\text { Explained } \\
\text { variation } \\
(\%)\end{array}$ \\
\hline Total & 233 & 339.5 & & \\
\hline Replication & 2 & 6.8 & & \\
\hline Genotype(G) & 12 & 69.0 & $5.7 * *$ & 20.3 \\
\hline Environment(E) & 5 & 109.3 & $21.8 * *$ & 32.2 \\
\hline $\mathbf{G} * \mathbf{E}$ & 60 & 71.4 & $1.1 * *$ & 21.1 \\
\hline Error & 154 & 83.0 & & \\
\hline
\end{tabular}

** Significant at $\mathrm{P} \leq 0.01$ probability level

\section{POLYGON VIEW OF GGE BIPLOT ANALYSIS OF MET DATA}

The polygon view of a biplot is the best way to visualize the interaction patterns between genotypes and environments (Yan and Kang, 2003) to show the presence or absence of cross over GE interaction which is helpful in estimating the possible existence of different mega environments (Gauch and Zobel, 1997; Yan and Tinker, 2006). Visualization of the "which won where" pattern of MET data is necessary for studying the possible existence of different mega environments in the target environment (Gauch and Zobel, 1997; Yan et al., 2000).Fig.1 represents a polygon view of upland rice genotypes MET data in this investigation. In this biplot, a polygon was formed by connecting the vertex genotypes with straight lines and the rest of the genotypes placed within the polygon. The vertex genotypes in this study were 8,2,9 and 12 . These genotypes were the best or the poorest genotypes in some or all of the environments because they were farthest from the origin of the biplot (Yan and Kang, 2003). From the polygon view of biplot analysis of MET data, the genotypes fell in four sections and the test environments fell in three sections. The first section contains the test environment WO-1 which had the genotype 9 as the winner; the second section contains the environments WO-3 and WO-5 with genotype 2 as the best yielder; the third section contains the test environments PA-3, PA- 6 and ME-7 with genotype 8 as the winner.This cross over GE suggests that the target environments may be divided in to three mega environments. However, it is not justifiable to consider WO-1 alone as mega environment for it is not a location by itself but representing one of the testing years at Woreta. No environments fell in to the sector of vertex genotype 12. This means that this genotype was not the winner in any of the environment; rather, it was likely to be the poorest genotypes in some or all of the environments. 


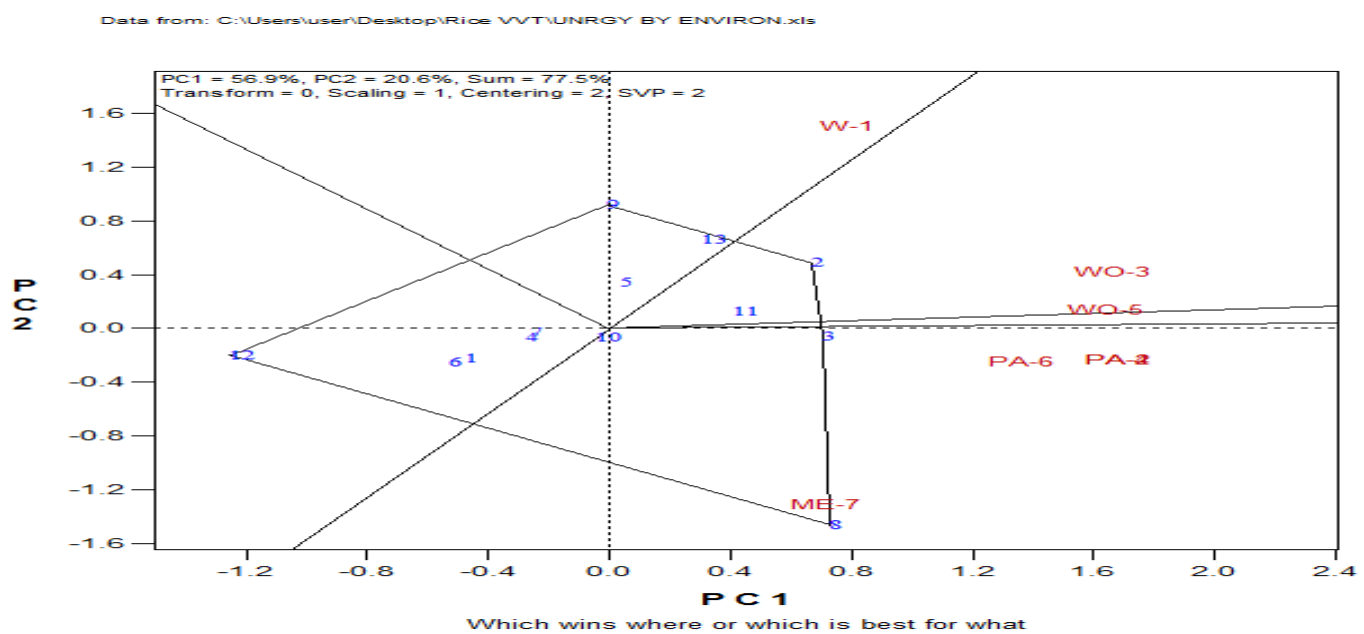

Figure 1: The which-won-where view of the GGEbiplot Note: WO=Woreta, $\mathrm{PA}=\mathrm{Pawe}$, $\mathrm{ME}=$ Metema

\section{MEAN YIELD AND STABILITY PERFORMANCE OF GENOTYPES}

Yield performance and stability of genotypes were evaluated by an average environment coordination (AEC) method (Yan, 2001; Yan and Hunt, 2002; Yan, 2002). In this method, an average environment is defined by the average PC1 and PC2 scores of all environments, represented by a small circle (Figure 2). A line is then drawn to pass through this average environment and the biplot origin; which is called the average environment axis (AEA) and serves as the abscissa of the AEC. The ordinate of the AEC is the line that passes through the origin and is perpendicular to the AEC abscissa (Figure 2). Unlike the AEC abscissa, which has one direction, with the arrow pointing to greater genotype main effect, the AEC ordinate is indicated by double arrows, and either direction away from the biplot origin indicates greater GEI effect and reduced stability. For selection, the ideal genotypes are those with both high mean yield and high stability. In the biplot, they are close to the origin and have the shortest vector from the AEC. In this study, genotype 3 followed by 11 can be considered as genotypes with both high yield and stability performance. The other genotypes on the right side of the line with double arrows have yield performance greater than mean yield and the genotypes on the left side of this line had yields less than mean yield. The genotypes with highest yielding performance but low stability were 8,2, 13 and 5 whereas the genotypes with low yield and low stability were 12,6 and 1. Yan and Kang (2003) noted that based on their grain yield and stability performance genotypes are classified in to three categories: (1) generally adapted, genotypes with high yield and stability performance (2) specifically adapted, genotypes with high mean yield but low stability performance and (3) adapted nowhere, genotypes with low grain yield and low stability performance. 


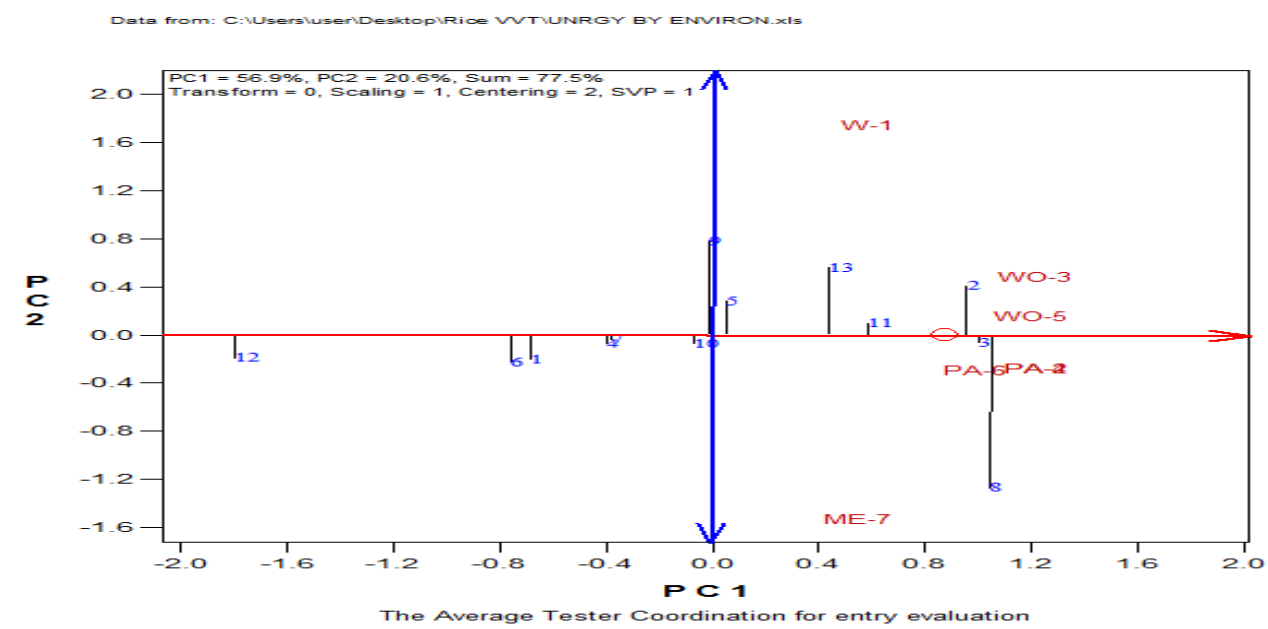

Figure 2: GGE biplot showing the ranking of genotypes for both yield and stability performance over environments Note: $\mathrm{WO}=$ Woreta, $\mathrm{PA}=\mathrm{Pawe}, \mathrm{ME}=$ Metema

\section{PERFORMANCE OF RICE GENOTYPES IN ALL ENVIRONMENTS}

To visualize the performance of each genotype in each environment both the genotype and environmental vectors are drawn (Fig 3). The performance of the genotype in an environment is better than average if the angle between its vector and the environment's vector is less than $90^{\circ}$; if the angle is greater than $90^{\circ}$ it is less than average and if the angle is about $90^{\circ}$ it is near to average (Yan and Tinker, 2006). Accordingly, genotypes 3, 11 and 2 (both Upland NERICA and non-NERICA ones) performed very well in almost all test environments. The remaining genotypes showed poor as well as good performances in different environments (Fig.3).

A genotype located nearer to the biplot origin has an average value in each of the environments. Such genotype has minimum contribution to both $G$ and GE interaction. Besides, the length of genotype vector measures the contribution of the genotype to either G or GEI or both (Yan and Tinker, 2006). Thus, genotypes 8,9 and 12 with the longest vector contributed to $\mathrm{G}$ and GEI. On the other hand, genotype 10 having very short vector and nearer to the biplot origin has very minimum contribution to both $\mathrm{G}$ and GEI.

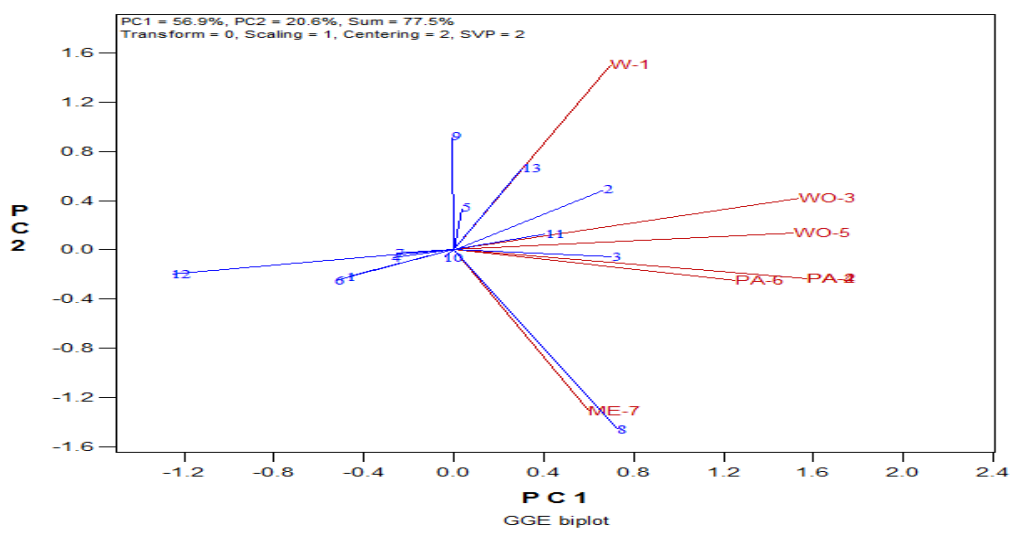

Figure 3: The GGEbiplot view showing the performance of each genotype in each environment Note: $\mathrm{WO}=$ Woreta, PA=Pawe, $\mathrm{ME}=$ Metema 


\section{EVALUATION OF GENOTYPES RELATIVE TO AN IDEAL GENOTYPE}

An ideal genotype should have the highest mean performance and be absolutely stable (Yan and Kang, 2003). Such an ideal genotype is defined by having the greatest vector length of the high yielding genotypes and with zero GEI, as represented by an arrow pointing to it (Figure 4). Although such an ideal genotype may not exist in reality, it can be used as a reference for genotype evaluation. Thus, using the ideal genotype as the center, concentric circles were drawn to help visualize the distance between each genotype and the ideal genotype. A genotype is more favorable if it is closer to the ideal genotype. Genotype 3 was near to the ideal genotype. Ranking of other genotypes based on the ideal genotype was $2>11>13>8$. In other words, the lower yielding genotypes $(12,6,1,4,7$, and 10) were unfavorable because they are far from the ideal genotype.

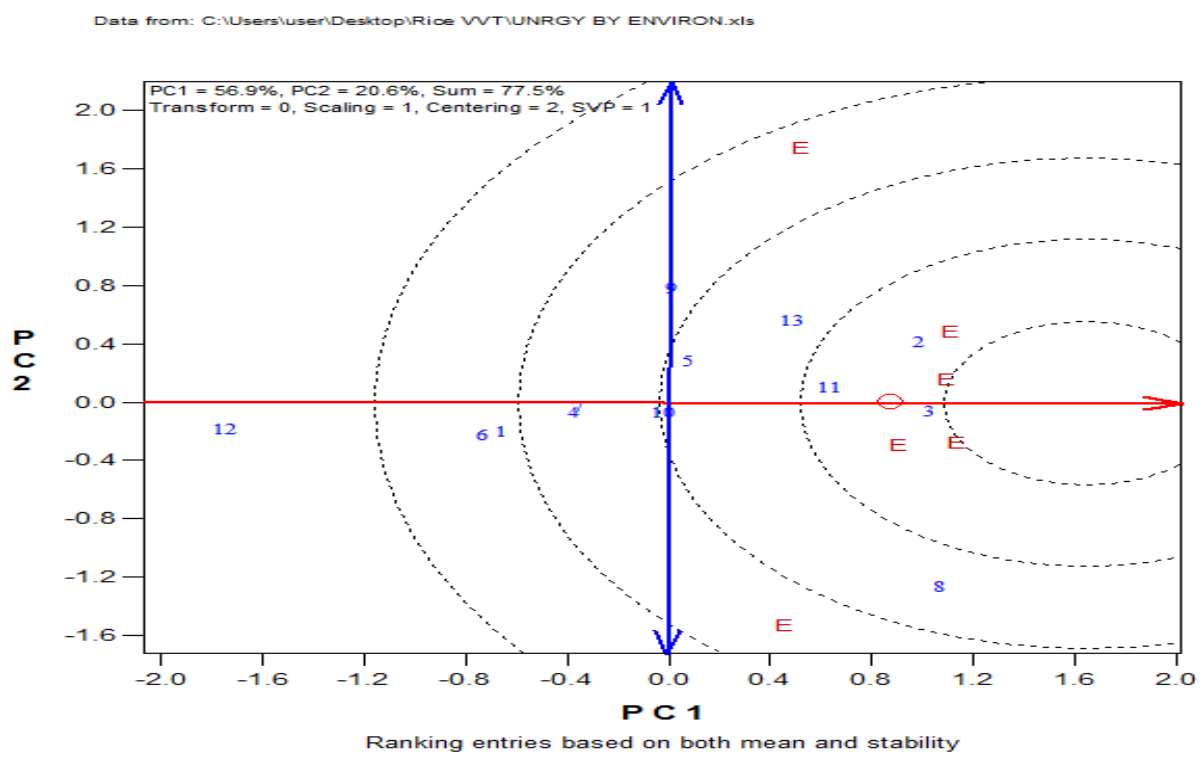

Figure 4: GGEbiplot of ideal genotype and comparison of the genotypes with the ideal genotype Note: $\mathrm{WO}=$ Woreta, $\mathrm{PA}=$ Pawe, $\mathrm{ME}=$ Metema

\section{RELATIONSHIPS AMONG TEST ENVIRONMENTS}

Fig. 5 provides the summary of the interrelationships among the test environments. The lines that connect the biplot origin and the markers for the environments are called environment vectors. The angle between the vectors of two environments is related to the correlation coefficient between them. The cosine of the angle between the vectors of two environments approximates the correlation coefficient between them (Kroonenberg, 1995; Yan, 2002). Acute angles indicate a positive correlation, obtuse angles a negative correlation and right angles no correlation (Yan and Kang, 2003). Based on the angles between environment vectors, the six environments fell in to three groups: WO-1, WO-3 and WO-5 (Woreta) formed group1, WO-3,WO-5 (Woreta) and PA-2, PA-6 (Pawe) formed group two and PA-2,PA-6 (Pawe) and ME-7(Metema) formed group three. The smallest angle between WO-5 and PA-2 implies that there was the highest correlation between them while the largest angle between WO-1and ME-7 indicates the poor 
correlation between these environments (Figure 5). Yan and Tinker (2006) and Kaya et al (2006) reported that the presence of close associations between testing environments reveals that similar information about the genotype could be obtained from fewer test environments and hence this could be an opportunity to reduce testing cost under limited resources.

Similarly, this tool was used for evaluation of interrelationships between 13 upland rice genotypes (Fig. 3). The overall picture of interrelationships between genotypes indicated that there were different genotype groups. In other words, these studied genotypes had diverse characteristics in terms of performance for grain yield and stability.

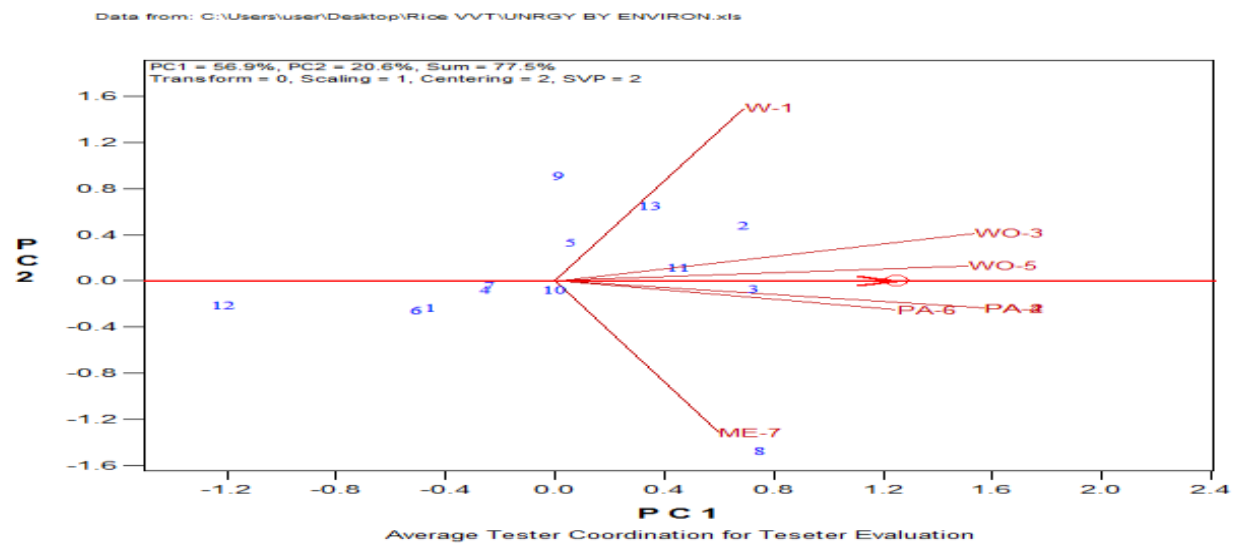

Figure 5: GGEbiplot on relationship among test environments Note: $\mathrm{WO}=$ Woreta, $\mathrm{PA}=$ Pawe, $\mathrm{ME}=$ Metema

\section{DISCRIMINATING ABILITY AND REPRESENTATIVENESS OF THE TEST ENVIRONMENTS}

Discriminating ability is an important measure of a test environment. A test environment which lacks discriminating ability provides no information about the cultivars and, therefore, it is useless (Yan and Kang, 2003). Another equally important measure of a test environment is its representativeness of the target environment. If a test environment is not representative of the target environment, it is not only useless but also misleading since it may provide biased information about the tested cultivars (Yan and Kang, 2003). GGE biplot discriminating ability of the genotypes and representativeness of the target environment is an important measure of the testing environments. The concentric circles on the biplot as shown in Fig. 6 help to visualize the length of the environment vectors, which is proportional to the standard deviation within the respective environments and is a measure of the discriminating ability of the environments. Therefore, among the six testing environments, WO-1 and ME-7 were the most discriminating (informative) while PA-6 was the least discriminating one (Fig.6). Test environments that are consistently non-discriminating (non-informative) provide little information on the genotypes and, therefore, should not be used as test environments (Yan and Tinker, 2006. The average environment (represented by the small circle at the end of the arrow) has the average coordinates of all test environments, and Average-Environment Axis (AEA) is the line that passes through the average environment and the biplot origin (Yan, 2002). A test environment that has a smaller angle with the AEA is more representative of other test environments. Thus, WO-5 and PA-2 
were the most representative environments whereas WO-1, WO-3, PA-6 and ME-7 were the least representative environments (Figure 6). Test environments (locations) that are both discriminating and representative are good test environments for selecting generally adaptable genotypes (Yan and Tinker, 2006). Hence, WO-5 and PA-2 were good test environments for selecting widely adapted genotypes. According to Yan and Tinker (2006), discriminating but non-representative test environments are useful for selecting specifically adaptable genotypes if the target environments can be divided into mega-environments or they are useful for culling unstable genotypes if the target environment is a single mega-environment. On the other hand, non-discriminating and non- representative environments are not useful. Thus, environments such as WO-1 and ME-7 were used to select specifically adapted genotypes while PA-6 was not useful test environment.

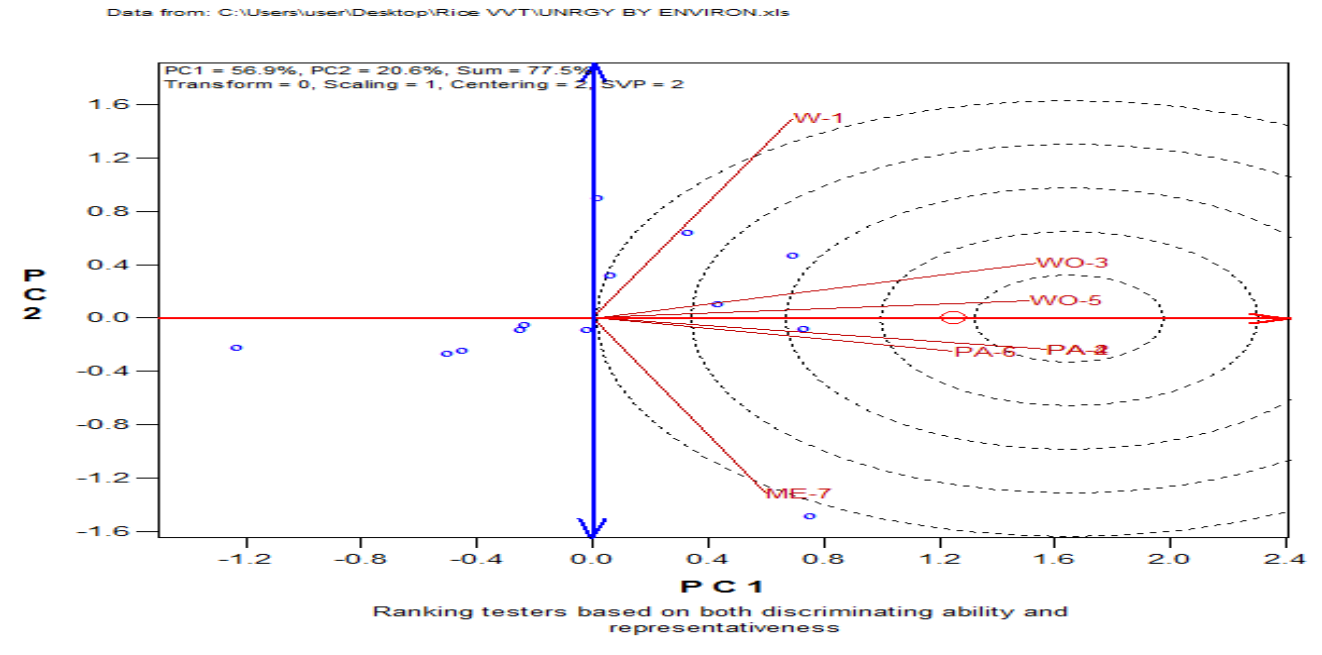

Figure 6: Discriminating and representativeness view of the GGEbiplot for the test environment Note: $\mathrm{WO}=$ Woreta, $\mathrm{PA}=$ Pawe, $\mathrm{ME}=$ Metema

\section{CONCLUSIONS AND RECOMMENDATIONS}

The result of this study indicated that upland rice yield performance was influenced by the environment effect followed by GEI and genotype. The magnitude of genotype effect was found almost equal to the GE interaction effect indicating the significant contribution of the genotypes to grain yield. The majority of tested genotypes exhibited crossover type of GEI revealed by their differential rankings across test environments; however, two genotypes showed non-crossover type of GEI.

GGEbiplot analysis allowed to visualize the "which-won-where" pattern of the genotypes, the ranking of genotypes based on both mean performance and stability, the inter-relationship among genotypes and between genotypes and environments, inter-relationship among environments the discriminating ability and representativeness of test environments and the interaction between genotypes and environments.

The 13 upland NERICA and non-NERICA rice genotypes showed variation for grain yield. In terms mean grain yield and stability performance, there were desirable genotypes such as 
genotype 3 while there were also genotypes with high grain yield but low in stability such as genotype 8 and there were genotypes such as genotype 6 with poor performance both in grain yield and stability. Regarding testing environments, there exist three possible megaenvironments. However, one of the them showed overlapping and it not justifiable to consider as independent mega-environment. The result of this study can be considered as a driving force for the national rice breeding program of the country to execute multi-location yield trials at a number of potential upland rice growing areas of the country. So that demand driven, economical and mega environment oriented breeding strategy can be designed and the effect of GEI can be either exploited or avoided as a result sustainable upland rice production would be secured in the country.

Among the tested genotypes included in this study, three genotypes (2, 3 and 8) were selected and promoted to verification based on their better performance in terms of grain yield, stability, farmers' preference and other desirable agronomic traits including earliness, medium to tall height, high spikelet fertility percentage, white seed color, big seed size and better disease reaction. Of which, genotype, 2 has been officially released by the national variety release standing committee of the country with the common name NERICA-12 for large scale production.

\section{REFERENCES}

[1] Balestre M, Vanderley BDS, Antonio AL, and Moises SR (2010). Stability and adaptability of upland rice genotypes .Crop breeding and applied biotechnology 10:357363.

[2] Ding M, B.Tier and W. Yan (2007). Application of GGE biplot analysis to evaluate Genotype $(G)$ Environment $(E)$ and $G \times E$ interaction on P. radiata: a case study. Paper presented to Australasian Forest Genetics Conference Breeding for Wood Quality, 1114 April 2007, Hobart, Tasmania, Australia.

[3] Fan XM, MS Kang, H Chen, Y Zhang, J Tan, and C Xu (2007) Yield stability of maize hybrids evaluated in multi-environment trials in Yunnan, China. Agron J 99: 220-228.

[4] Flores F, MT. Moreno and JI. Cubero (1998). A comparison of univariate and multivariate methods to analyze environments. Field Crops Res 56:271-286.

[5] Gabriel, K. R. (1971). The biplot graphic display of matrices withapplication to principal component analysis. Biometrika 58: 453-467.

[6] Gauch HG and RW. Zobel (1996): AMMI analysis of yield trials. In M.S. Kang \& Gauch H.G. eds. Genotype-by-environment interaction, pp 85-122. Boca Raton, FL, CRC Pres Gauch HG, Piepho HP, Annicchiarico P (2008). Statistical analysis of yield trials by AMMI and GGE: Further considerations. Crop Sci 48:866-889. Gauch, GH. and RW. Zobel (1997). Interpreting mega-environments and targeting genotype Crop Sci. 37: 311 326.

[7] GGE-biplot, (2009). GGE-biplot software version 5.2. The complete biplot analysis system: GGEbiplot pattern explorer. Copy right Weikai Yan, 2001-2009, USA.

[8] Gomez KA. and Gomez AA. (1994). Statistical procedures for agricultural research. 2nd edition. John Willey and Sons.

[9] Kaya Y, M. Akcura, and S.Taner (2006). GGE-biplot analysis of multi-environment yield trials in bread wheat. Turk J. Agric. 30:325-337. 
[10] Kroonenberg PM. (2005) Introduction to biplots for $G \times E$ tables. Department of Mathematics, Research Report \#51, University of Queensland, 22.

[11] Matus-Cadiz MA, P. Hucl, CE. Perron and RT. Tyler (2003) Genotype x environment interaction for grain color in hard white spring wheat. Crop Sci 43: 219-226

[12] Ministry of Agriculture and Rural Development (MoARD), (2010). National Rice Research and Development Strategy of Ethiopia. Addis Ababa, Ethiopia, pp. 48.

[13] SAS., (2004). System analysis software. Version 9.1.2. SAS institute Inc., Cary, North Carolina, USA.

[14] Yan W. (2001). GGEbiplot- a Windows application for graphical analysis of multienvironment trial data and other types of two-way data. Agron J 93:1111-1118.

[15] Yan, W.(2011). GGEbiplot vs AMMI graphs for genotype-by-environment data analysis.

[16] Journal of IIndian Society of Agricultural Statistic . 65(2):181-193.

[17] Yan W and LA. Hunt (2002). Biplot analysis of diallel data. Crop Sci 42:21-30.

[18] Yan, W and I. Rajcan. (2002). Biplot analysis of test sites and trait relations of soybean in Ontario. Crop Sci. 42: 11-20.

[19] Yan, W and L.A. Hunt. (2001). Interpretation of genotype $x$ environment interaction for winter wheat yield in Ontario. Crop Sci. 41: 19-25.

[20] Yan, W., L.A. Hunt, Q. Sheng and Z. Szlavnics. (2000). Cultivar evaluation and megaenvironment investigation based on the GGE biplot. Crop Sci. 40: 597-605.

[21] Yan W. and MS Kang (2003) GGE biplot analysis: A graphical tool for breeders, geneticists, and agronomists. CRC Press, Boca Raton, FL.

[22] Yan W. and NA. Tinker (2006) Biplot analysis of multi-environment trial data: Principles and applications. Can J Plant Sci 86: 623-645

[23] Zoble RW, MJ. Wright and HG. Gauch (1988). Statistical analysis of a yield trial. Agron J 80:388- 393. 